Revista Qualidade Emergente, 2015, V. 6, N. 1:01-12

\title{
GESTÃO DA QUALIDADE ATRAVÉS DA METODOLOGIA QRQC - ESTUDO DE CASO EM UMA EMPRESA DO SETOR AUTOMOTIVO
}

Laís de Lima Rocha

Jislaine Figueira Coradél Coltro

Adriana Roseli Wunsch Takahashi

Karen Menger da Silva Guerreiro

Thalita Toshie de Jesus Shibuya

\section{Introdução}

Ao longo dos anos, as Escolas de Administração têm demonstrado uma crescente preocupação com a qualidade. No início, esses estudos eram baseados em produtividade, custos e não conformidades. Com o processo de modernização da produção, as organizações passaram a se preocupar não somente com custos e produção, mas também com a redução de desperdícios e otimização de processos. Diversos autores ressaltam que a busca da qualidade, hoje, também abrange a busca pela excelência, inovação constante, criando diferencial competitivo.

Para que isso aconteça, um planejamento estratégico baseado na qualidade é essencial, tendo como objetivo um melhor gerenciamento através de ferramentas específicas. Neste contexto, para que a empresa possa realizar uma tomada de decisão eficaz, é necessário que se identifique as ferramentas que mais se adaptam a sua realidade.

Entretanto, nem sempre uma ou duas ferramentas são capazes de suprir as necessidades da organização. Neste caso é possível trabalhar com um conjunto de ferramentas que se inter-relacionem formando um processo de identificação e resolução dos problemas da qualidade. (CORREIA \& CORREIA, 2008; FARIAS \& SALLES, 2007; LAUGENI \& MARTINS, 2005; PALADINI, 2009). Neste contexto, se insere o presente estudo de caso onde são trabalhadas 4 ferramentas da qualidade de maneira sequencial: 5 W2H, Diagrama de Ishikawa 5 Por Quês e Diagrama de Pareto, utilizando a metodologia QRQC - Quick Response to Quality Control (Resposta Rápida para o Controle de Qualidade).

Porém, quando se trata da implantação de um novo método ou ferramenta, sempre existem questões que dificultam o processo, sejam elas de âmbito estrutural ou até mesmo pela falta de conhecimento básico da qualidade. Sendo assim, apresenta-se o problema de pesquisa proposto: De que maneira foi realizada a implantação da Metodologia QRQC na Empresa Alfa? 
Ao todo, o artigo está organizado em 4 seções, além desta introdução. Na próxima seção, apresenta-se o referencial teórico onde é abordado sobre o método QRQC e a sua relação com as ferramentas da qualidade. Em seguida, na seção 3, é descrito o método de pesquisa, com as informações gerais sobre da empresa e o perfil dos entrevistados. Logo após, na seção 4, é relatado o estudo de caso e seus impactos, e finalizando, na seção 5 , a conclusão, com a análise geral do estudo.

\section{Referencial teórico}

Antes de apresentar este estudo é importante estabelecer a diferença entre Metodologia e Ferramenta. De acordo com Valeriano (2005, p. 122) "a metodologia é definida por um grupo de processos que caracterizam o planejamento, a execução e o controle das atividades e seus resultados". Seleme e Stadler (2008, p. 24) definem metodologia sendo uma "sequencia lógica empregada para atingir o objetivo desejado, enquanto ferramenta é um recurso utilizado no método" .

Nesse sentido, o QRQC - Quick Response to Quality Control (Resposta Rápida para o Controle de Qualidade) é considerado como uma metodologia de gerenciamento à vista, pois inclui as principais ferramentas da qualidade para a análise e identificação de problemas decorrentes no processo produtivo, sendo utilizado principalmente em indústrias automobilísticas. Segundo Gonzalez \& Martins (2011, p. 7) o QRQC

\footnotetext{
"promove ações de melhoria e correção dos processos no momento da identificação da oportunidade ou do desvio, abordando os seguintes fatores: objeto de melhoria, problema identificado, causa do problema, ação a ser tomada para correção, responsável pela ação de melhoria e prazo para conclusão"
}

As ferramentas 5W2H, Diagrama de Ishikawa, 5 Por Quê's e Diagrama de Paretto compõe a metodologia que é dividida em 8 fases, denominadas 8D's. A primeira ferramenta, $5 \mathrm{~W} 2 \mathrm{H}$, provém das seis perguntas em inglês: What $(\mathrm{O}$ que), Who (quem), Where (onde), When (quando), Why (por quê) e How (como) e posteriormente foi acrescentado mais um $\mathrm{H}$ de How Much( quanto custa) a fim de embasar financeiramente a decisão tomada. Os autores também ressaltam que o resultado dessas perguntas não é uma exposição clara das falhas, mas sim uma indicação mais precisa da causa do problema. (SELEME \& STADLER, 2008; PARANHOS, 2007; GOMES, 1998; SEBRAE, 2005).

O Diagrama de Ishikawa é apontado pelos autores como eficazes na identificação das possíveis causas-raízes, utilizados rotineiramente após uma Análise de Pareto, onde os problemas classificados como mais importantes serão foco de análise do diagrama espinha de peixe. Sua aplicação consiste em identificar o problema colocando-o no lugar onde ficaria a cabeça do peixe, ramificando as possíveis causas e causas raízes na espinha dorsal do peixe que será estruturada de acordo com a lógica dos 6M's: máquina, material, meio ambiente, método, mão de obra e meio de medida. Os autores explicam que os 6M's auxiliam na identificação das causas principais, já as causas secundárias podem 
ser identificadas concentrando-se no 5W2H. (ISHIKAWA, 1993; CORREIA \& CORREIA 2009; VERGUEIRO, 2002; BROCKA \& BROCKA, 1994).

Para Seleme e Stadler (2008, p. 43) a aplicação dos 5 Por Quê's como análise do problema tem como objetivo identificar a sua causa raiz. Ainda de acordo com os autores deve-se realizar a pergunta por quê quantas vezes forem necessárias, " estruturando o pensamento" para se identificar a verdadeira causa do problema, direcionando para ação que efetivamente o solucionara. Ao se perguntar cinco vezes por quê e respondendo cada questionamento, Ohno (1997, p. 37-38) afirma "que pode-se chegar a verdadeira causa do problema, que geralmente está escondida atrás dos sintomas mais óbvios."

Werkema (1995) descreve que o Princípio de Pareto estabelece que os problemas relacionados a qualidade sejam classificados em "poucos vitais", os de menor número porém que trazem grandes perdas, e os "muito triviais", que são a grande maioria dos problemas, mas que se convertem em perdas pouco significativas. A autora acrescenta ainda que num primeiro momento deve-se focar nos poucos vitais, para que os problemas possam ser resolvidos da forma mais eficiente possível. "Nesse sentido, o gráfico idealizado permite que sejam identificados e classificados aqueles problemas de maior importância e devem ser corrigidos primeiramente." (SELEME \& STADLER, 2008, p. 88).

Na metodologia QRQC, essas ferramentas são usadas sequencialmente, buscando tratar o problema na sua causa-raíz, evitando a reincidência. Além disso, é possível a administração do tempo de forma mais eficaz, pois em cada fase, existe um prazo para a concretização das ações. A metodologia também é muito dinâmica, pois envolve equipes multifuncionais, atuando em todos os níveis da organização, o que facilita o processo de integração entre o chão de fábrica e a direção, melhorando o clima organizacional e quebrando as barreiras culturais.

Em uma descrição mais prática sobre o QRQC, por se tratar de gestão visual, todas as ferramentas ficam em um único formulário, flipchart, de tamanho A1 $(59,4 \times 84,1 \mathrm{~cm})$, onde as informações são apresentadas de maneira prática e rápida. Cada flipchart é utilizado para a tratativa de um único problema, sendo que cada folha de flipchart é denominada pela empresa como um QRQC, desta forma, um QRQC finalizado significa um problema resolvido. Além do preenchimento do formulário, todos os dados são disponibilizados em um quadro de acompanhamento, que é atualizado diariamente, conforme descrito por um dos entrevistados.

A seguir é apresentado um quadro-resumo com as ferramentas da qualidade e suas respectivas funções em cada fase do QRQC:

\begin{tabular}{|l|l|l|l|}
\hline Fases do QRQC & Ferramenta & $\begin{array}{l}\text { Descrição } \\
\text { da } \\
\text { ferramenta }\end{array}$ & Aplicação / Objetivo \\
\hline
\end{tabular}




\begin{tabular}{|c|c|c|c|c|}
\hline D1 & $\begin{array}{l}\text { Definição } \\
\text { do } \\
\text { Problema }\end{array}$ & \multirow{3}{*}{$5 \mathrm{~W} 2 \mathrm{H}$} & \multirow{3}{*}{$\begin{array}{c}\text { Etapas } \\
\text { estruturadas a } \\
\text { partir das } \\
\text { perguntas: O que? } \\
\text { Quem? Onde? } \\
\text { Quando? Por quê? } \\
\text { Como? Quanto? }\end{array}$} & $\begin{array}{l}\text { Investigação da } \\
\text { causa do problema; } \\
\text { Levantamento de } \\
\text { hipóteses. }\end{array}$ \\
\hline D2 & $\begin{array}{l}\text { Risco em } \\
\text { Outros } \\
\text { Produtos }\end{array}$ & & & $\begin{array}{c}\text { Garantir que o } \\
\text { problema não vai se } \\
\text { expandir; Evitar } \\
\text { esforços } \\
\text { desnecessários. }\end{array}$ \\
\hline D3 & Contenção & & & $\begin{array}{l}\text { Ações imediatas para } \\
\text { resolução do } \\
\text { problema; Garantir } \\
\text { que as não } \\
\text { conformidades } \\
\text { cheguem ao cliente. }\end{array}$ \\
\hline \multirow[t]{2}{*}{ D4 } & \multirow{2}{*}{$\begin{array}{l}\text { Causa da } \\
\text { Não } \\
\text { Detecção }\end{array}$} & $\begin{array}{l}\text { Diagrama } \\
\text { de } \\
\text { Ishikawa }\end{array}$ & $\begin{array}{l}\text { Identificação dos } \\
\text { fatores das causas- } \\
\text { raízes }\end{array}$ & $\begin{array}{c}\text { Desmembrar o } \\
\text { problema para } \\
\text { identificar suas sub- } \\
\text { causas }\end{array}$ \\
\hline & & \multirow[t]{2}{*}{5 Por quês } & \multirow{2}{*}{$\begin{array}{c}\text { Busca pela } \\
\text { verdadeira causa do } \\
\text { problema, } \\
\text { descartando os } \\
\text { sintomas mais } \\
\text { óbvios. }\end{array}$} & $\begin{array}{c}\text { Por que o problema } \\
\text { não foi detectado? } \\
\text { Por que aconteceu o } \\
\text { problema? }\end{array}$ \\
\hline D5 & $\begin{array}{l}\text { Causa da } \\
\text { Ocorrência }\end{array}$ & & & $\begin{array}{c}\text { Apresentação e } \\
\text { discussão do } \\
\text { problema }\end{array}$ \\
\hline D6 & Ações Corretivas & Formulário QRQC & Plano de Ação & $\begin{array}{l}\text { Desenvolvimento e } \\
\text { monitoramento das } \\
\text { ações propostas }\end{array}$ \\
\hline D7 & $\begin{array}{l}\text { Acompanhamento } \\
\text { de } \\
\text { Reincidência }\end{array}$ & $\begin{array}{l}\text { Diagrama de } \\
\text { Paretto }\end{array}$ & $\begin{array}{l}\text { Gráfico que auxilia } \\
\text { na identificação dos } \\
\text { problemas mais } \\
\text { significativos }\end{array}$ & $\begin{array}{c}\text { Acompanhamento } \\
\text { quantitativo das } \\
\text { ações realizadas até } \\
\text { a fase D6 }\end{array}$ \\
\hline D8 & Lições Aprendidas & & ão e registro & resultados. \\
\hline
\end{tabular}

Quadro 1 - As ferramentas da qualidade e suas respectivas funções em cada fase do QRQC 
Fonte: Desenvolvido pelas autoras com base em Broka \& Broka (1994); Correa \& Correa (2009); Ishikawa (1993); Juran (1991); Ohno (1997); Paranhos (2007); Sashkin (1994);SEBRAE (2005); Seleme \& Stadler (2008); Vergueiro (2002); Werkema (1995).

Como pode ser observado, nas etapas D1 até a D3, é utilizada a ferramenta $5 \mathrm{~W} 2 \mathrm{H}$ para investigação das causas, focando esforços para conter o problema antes que ele possa atingir outras linhas, lotes ou clientes. No D4 é feita uma análise através do Diagrama de Ishikawa e logo após é aplicada a técnica dos 5 Por Quês, onde inicialmente será demonstrado por que o problema não foi detectado, sendo também utilizado na etapa D5 para evidenciar por que aconteceu o problema, buscando suas causas-raízes.

Por meio do Plano de Ação, na etapa D6, são definidas as ações tratando o problema de forma definitiva. Essas ações são quantificadas na etapa D7 pelo Diagrama de Paretto, onde irá ocorrer o monitoramento dos dados por um determinado período e não havendo reincidência, é iniciada a etapa final. O QRQC é concluído na etapa D8 quando os resultados das ações são apresentados e incorporados ao Plano de Trabalho da Organização, com treinamentos e padronização de procedimentos.

A partir deste referencial, apresenta-se a seguir os procedimentos metodológicos utilizados para a conclusão da presente pesquisa.

\section{Método de pesquisa}

O presente trabalho foi desenvolvido por meio do estudo de caso, que de acordo com Gil (2009) é utilizado para descrever a situação a partir do contexto em que está sendo feita determinada investigação. Para tanto, foram realizadas entrevistas semi-estruturadas, definidas por Severino (2007) como "coleta de informações diretamente solicitadas aos sujeitos pesquisados", onde as perguntas formuladas foram direcionadas e previamente estabelecidas.

Este estudo de caso foi realizado em uma organização de grande porte, fundada na década de 70, no estado de Minas Gerais, contando hoje com 6 unidades de negócio. A unidade analisada neste trabalho está situada na região metropolitana de Curitiba, Paraná, onde atua como fornecedora de sistemas automotivos e conjuntos soldados para as maiores montadoras do Brasil.

Esta empresa foi selecionada como objeto de estudo devido sua relevância no mercado automobilístico local, pela a aplicação de conceitos da qualidade e principalmente por trabalhar com a metodologia QRQC. A empresa solicitou que fosse mantido anonimato, sendo aqui denominada pelas autoras como Empresa Alfa.

A fim de coletar dados para sustentar o estudo de caso, foram realizadas entrevistas com 2 membros da organização estudada, sendo ambos atuantes na metodologia QRQC. O Entrevistado A, com idade entre 45 e 50 anos, atuando na empresa há 2 anos como Engenheiro da Qualidade e o Entrevistado B, idade entre 25 e 30 anos, atuando como Supervisor da Qualidade, há 4 anos na empresa. 
Os principais pontos abordados na entrevista foram a explanação do processo de implantação da metodologia bem como os impactos identificados durante este processo.

\section{Estudo de caso}

Antes da implantação do QRQC, a empresa já trabalhava com a abordagem 8D, por meio de formulários avulsos, sendo que os dados eram armazenados individualmente em papel ou computador, dificultando a sua análise. Conforme o relato do Entrevistado B, havia muita dificuldade na análise e tratativa dos problemas, pois faltava o conhecimento para identificar a melhor ferramenta a ser utilizada para determinada falha: "você não conseguia manter uma organização de todo trabalho que era feito (...), utilizavam-se as ferramentas do sistema de gestão, mas você não estava atendendo da melhor maneira o processo".

Ainda de acordo com o Entrevistado B, não havia um ponto de partida para se chegar à causa raiz e as ações eram ineficazes para os problemas. Assim, se ocorresse um erro no início da análise, aquela ação não teria o resultado esperado. Já o entrevistado A relata que a empresa recebia uma quantidade de reclamações que não era possível de se administrar. Além disso, o entrevistado B também descreve que o volume de peças não conforme era três vezes maior que número de peças dentro das especificações. "Era um absurdo, era muito desperdício, muito refugo, muito retrabalho".

A iniciativa da implantação do QRQC partiu do Engenheiro da Qualidade, que já conhecia a metodologia, conforme descrito pelo entrevistado B. Inicialmente, a metodologia foi implementada em uma célula de produção, em novembro de 2009, na qual o planejador também já tinha experiência com o método, o que facilitou a aplicação. $O$ entrevistado A relata que foi realizada uma auditoria pelo cliente nesta célula e o resultado do trabalho foi elogiado para a direção. "A direção viu que era uma ferramenta útil e que foi aprovada pelo nosso cliente, então teve uma aceitação a nível global”. (Entrevistado A).

Após três meses, inicia-se o projeto de aplicação nas outras células. O Entrevistado B salienta que foi feito um benchmarking interno, de célula para célula, aproveitando os melhores desempenhos para resultado de todo o conjunto, criando assim uma padronização, "aprimoramos a sistemática da discussão, da troca de informações". Outro fator que facilitou a implantação foi à participação de funcionários que trouxeram seus conhecimentos de experiências anteriores.

Segundo o Entrevistado B, como a direção também não conhecia a metodologia, houve um grande envolvimento no sentido de avaliar e direcionar a gestão das ferramentas. Considerando que a qualidade é algo que está intrínseco dentro da empresa, partindo da direção, a metodologia foi de encontro aos princípios da qualidade que regem a organização.

Apesar da convergências de valores, a primeira dificuldade diagnosticada na entrevista foi a resistência cultural dentro da empresa com a nova metodologia, tanto que foi necessária a troca de gestão, sendo realizada uma mudança radical, conforme relatado 
pelo Entrevistado B. E complementa afirmando que foi feito um grande trabalho de conscientização para fosse absorvida a nova filosofia que estava sendo proposta.

Entretanto, o Entrevistado A salienta que todo processo de implantação de uma nova metodologia encontra certa resistência inicial: "fazer mudar de um sistema de trabalho que era utilizado nos primórdios, desde o inicio dos procedimentos, de quando foi implantado o sistema da qualidade, para introduzir alguma coisa nova, uma resistência inicial foi colocada". (Entrevistado A.) Entretanto, a aceitação veio com o tempo, por meio da comprovação de que a metodologia é eficaz, pois agrega valor e traz resultados.

Uma das dificuldades encontradas descrita pelo Entrevistado B foi falta de padronização do conhecimento com relação às ferramentas. Os diversos níveis de instrução dos envolvidos causavam dificuldades no entendimento das etapas do QRQC. Assim, o aprendizado foi através do desenvolvimento mútuo, proporcionado pelas reuniões e trocas de experiências.

\subsection{Os impactos da implantação}

O fato de a empresa trabalhar com outsourcing, através de produção puxada, atendendo ao cliente na sistemática Just In Time, no qual o fator tempo é determinante, também foi outro ponto identificado nas entrevistas como uma dificuldade inicial para a implantação do QRQC. O grande fluxo de produção e os prazos estreitos de entrega impediam a interrupção do processo produtivo para a tratativa do problema. O Entrevistado $B$ descreve que essa situação chegou a tal ponto que tiveram que parar toda a produção. Nesse momento houve o apoio da direção, pois como já citado anteriormente, a qualidade é um dos princípios norteadores da organização. "Você sabe que é muito melhor você parar, do que você acabar parando o cliente por um problema de qualidade seu". (Entrevistado B). Porém, o Entrevistado B também salienta que é muito importante conhecer o processo do cliente e buscar uma estratégia que cause o mínimo de impacto possível. Já o entrevistado $A$ diz que na metodologia anterior, os prazos de resposta não eram cumpridos, o que prejudicava a imagem da empresa. Com o QRCR esses prazos são administrados na data correta, gerando uma maior confiabilidade perante o cliente.

Também foram desenvolvidas novas abordagens com relação aos fornecedores. Passou- se a monitorar o desempenho através de um histórico de gerenciamento de não conformidades. Depois, é feito um work shopping com os principais fornecedores onde são apresentados os resultados dos seus desempenhos, e desenvolvidas metas para a redução do número de não conformidades e reclamações. Essas metas são formalizadas através de uma carta de compromisso, transformando fornecedores em parceiros.

Sobre os processos internos na empresa, o entrevistado A salienta que os resultados podem ser medidos através dos indicadores e da quantidade de reclamações, sendo que a diferença de desempenho entre 2009 e 2010 pode ser percebida por todos os colaboradores. Já o Entrevistado B descreve que houve a melhoria de vários processos, principalmente na conscientização dos colaboradores, que passaram a entender a 
importância do cumprimento de cada etapa do processo, "ele passa a ser um conhecedor não só daquela atividade que ele executa, mas do processo”. (Entrevistado B).

Esse envolvimento gera motivação entre os colaboradores, pois eles tornam-se parte fundamental do processo. Esse fato pode ser percebido quando o Entrevistado B relata que as reuniões passaram a ser realizadas no chão de fábrica, contando com a participação direta do operacional.

[...] a equipe multifuncional participa para análise da discussão e a partir daquela discussão em mesa, você vai posto de trabalho observar, e nesse momento o operador participa efetivamente. [...] Às vezes o técnico, engenheiro, o líder vai ao processo e não consegue enxergar o que precisa ver, ai conversa com operador $e$ operador fala que isso é questão de determinada ocasião e ai você consegue compreender.

Com relação aos custos, a implantação teve um investimento financeiro mínimo, sendo apenas a confecção de formulários em tamanho apropriado e treinamento para toda liderança. "Isso é custo zero praticamente". (Entrevistado A). Além do baixo investimento, o QRCQ trouxe a redução de custos pela não reincidência dos problemas, "pois cada reclamação gerava um custo administrativo, (...) gerando uma economia de milhares de reais". (Entrevistado $A)$.

Os resultados foram tão benéficos, que hoje a metodologia está se expandindo por todas as unidades e conforme salienta o entrevistado $A$, já está padronizada nos procedimentos corporativos. Além disso, o Entrevistado A também ressalta que o QRQC atende a ISO TS em sua integridade, diferente de outras metodologias.

Em linhas gerais, pelo que se pôde observar nas entrevistas, houve uma melhoria significativa quanto à diminuição de não conformidades e reclamações. De acordo com o Entrevistado A, após a introdução da metodologia a melhora foi de mais de $90 \%$ nos resultados. "Hoje nós temos uma, duas ou três reclamações mensais e estão administráveis, nós tínhamos isso por dia, quatro ou cinco reclamações por dia!". (Entrevistado A).

Já o impacto negativo foi à resistência à mudança, pois inicialmente ocorreram dificuldades na aceitação da metodologia. Entretanto, com a melhoria dos resultados a aderência ao QRQC foi aumentando, tanto que atualmente ele está sendo expandido para todas as unidades da organização, fazendo parte do procedimento corporativo da empresa. Depois que o choque inicial foi amenizado, identificou-se outro problema: a falta de conhecimento das pessoas em relação às ferramentas da qualidade. Com a aplicação da própria metodologia proporcionou que esse conhecimento fosse nivelado.

A implantação de algo novo dentro de uma estrutura que já está consolidada nunca é tarefa fácil. E com a Empresa X não foi diferente. A adoção da metodologia QRQC surgiu da necessidade de mudanças e apesar de já trabalhar com a política da qualidade, os resultados obtidos não eram satisfatórios. A empresa chegou a um ponto onde era quase impossível a administração da quantidade de reclamações que recebia. Além disso, havia 
extrema necessidade de uma resposta rápida ao cliente. Conforme relato dos entrevistados, os prazos não cumpridos prejudicavam a imagem da empresa, além de originar retrabalho e prejuízos.

Algumas empresas do segmento automotivo já trabalhavam com a metodologia e foi devido à experiência positiva de alguns profissionais que atuavam nessas organizações, é que o QRQC foi apresentado a Empresa $X$. A adesão foi imediata já que esse método se enquadra perfeitamente nas normas da ISO relativas ao setor automotivo, além de apresentar resultados rápidos e eficazes.

A metodologia atua no problema de forma definitiva, evitando a reincidência. Quando uma não conformidade é identificada pelo cliente, inicia-se um QRQC para fazer a contenção da ocorrência e buscar soluções para extinguir definitivamente o problema. Assim, a reincidência é quase inexistente, pois o processo busca a identificação da causa raiz, agindo diretamente no fator gerador do problema. Dessa forma, os recursos e o tempo são otimizados, permitindo que a organização invista em novos projetos.

\section{Considerações finais}

Considerando então os pontos positivos e negativos da metodologia, pode-se concluir que a implantação do $Q R Q C$ na Empresa $X$ apresentou bons resultados. Além da redução dos índices de reclamações, foi possível também identificar a diminuição dos custos com não conformidades, a melhoria nos processos internos e também a melhoria do gerenciamento e do tempo de resposta ao cliente.

O bom desempenho da metodologia QRQC também se deve ao fato que a Empresa $X$ tem a qualidade como um de seus princípios norteadores. Conforme descrito pelo Entrevistado B, "a qualidade é soberana dentro da empresa". Dessa forma, a qualidade passa a estar tão envolvida na filosofia da organização, que se torna uma responsabilidade de todos.

Dentre os pontos positivo e negativos identificados no processo de implantação da Metodologia QRQC, observou-se:

\section{Elementos facilitadores}

- Fácil aplicação: se bem aplicada e bem gerenciada, a metodologia faz a tratativa do problema de forma definitiva, evitando a reincidência.

- Melhoria contínua: cada problema é tratado de forma definitiva, possibilitando que o tempo e os recursos gastos com o retrabalho sejam melhor aplicados.

- Gestão Visual: para cada QRQC é utilizado um formulário tamanho A1, adaptado para flipchart. Após, cada QRQC em tratamento é descriminado de forma resumida em um quadro no chão de fábrica, tornando os dados mais visíveis e de fácil, assim como os prazos de conclusão. Outro ítem implementado na empresa foi às instruções de trabalho em forma de desenho, definidas pelos entrevistados como Poka-Yoke visuais, para facilitar aos funcionários um melhor entendimento das atividades, evitando erros pela falta de compreensão dos procedimentos. 
- Custo Baixo: o investimento foi de confeccionar formulários no tamanho A1 e ministrar treinamento para os lideres.

- Aprendizagem contínua: ao final de cada QRQC existe um item a ser preenchido denominado Lições Aprendidas, onde a experiência adquirida servirá como aprendizado e será disponibilizada para o conhecimento de todos.

- Integração de toda a empresa: são realizadas reuniões com uma equipe multifuncional, onde cada área relacionada com o problema tratado deve participar. Isso permite o dinamismo das informações e o envolvimento de toda a organização.

Elementos dificultadores:

- A aplicação da metodologia depende diretamente do fator humano: nem todas as pessoas possuem o mesmo grau de envolvimento e isso dificulta que a metodologia seja aplicada na íntegra, pois de acordo com o Entrevistado A, "nem todos os líderes tem a mesma cabeça e a mesma atitude".

- Necessidade de monitoramento contínuo: devido aos prazos de resposta, o QRQC depende de acompanhamento direto, sendo necessário que uma pessoa responsável pela área esteja em contínua atenção para o atendimento dos prazos.

- Falta de conhecimento das ferramentas da qualidade: se os envolvidos do processo não tiverem conhecimento das ferramentas da qualidade, o QRQC não terá a eficácia desejada.

No geral, pode-se verificar que a implantação do QRQC teve muito mais impactos positivos do que negativos, e que a metodologia escolhida trouxe grandes benefícios para a organização. Embora os resultados obtidos tenham sido satisfatórios para o objetivo deste estudo, recomenda-se uma análise mais profunda da organização, para que assim, os resultados sejam confirmados.

A empresa deve ter a qualidade como filosofia, não como requisito. Dessa forma, o processo de implantação de qualquer ferramenta fica mais fácil, pois com o apoio da direção, os colaboradores se sentem mais envolvidos no processo de implantação. E esse é o primeiro passo para a conquista dos seus objetivos.

Analisando a aplicação das ferramentas foi possível identificar uma possível falha de denominação do Diagrama de Pareto, porém não fica clara a relação desse diagrama com a teoria apresentada, pois os autores enfatizam que essa ferramenta é utilizada para a análise de vários problemas, com o propósito de identificar os mais relevantes, que causam mais impacto na organização. Na abordagem do QRQC, esse gráfico demonstra apenas a quantidade de ocorrências, se aproximando mais de um histograma.

Outro ponto analisado foi a ordem de utilização das ferramentas, sendo que na metodologia QRQC é aplicado primeiro o $5 \mathrm{~W} 2 \mathrm{H}$, depois o Diagrama de Ishikawa, seguido do Diagrama de Pareto e finalizando com 5 Por Quê's, porém de acordo com o referencial teórico, o Diagrama de Ishikawa normamente é utilizado depois do Diagrama Pareto, pois o problema mais relevante é desmembrado nos 6M's. A literatura também apresenta que o $5 \mathrm{~W} 2 \mathrm{H}$ faz a análise das causas secundárias, sendo então, de acordo com a teoria, a 
ordem correta a utilização do Diagrama de Pareto, seguido do Diagrama de Ishikawa e $5 \mathrm{~W} 2 \mathrm{H}$. E nos dois casos finalizando com 5 Por Quês. Dessa forma, sugere-se o estudo da aplicação da metodologia com a ordem das ferramentas baseadas na teoria apresentada, comparando os resultados.

Outro ponto que também merece atenção é a escassez de literatura referente à metodologia QRQC, pois de acordo com um dos entrevistados, ela já á aplicada no setor automobilístico há algum tempo. Neste contexto também fica como sugestão para estudos futuros a pesquisa desta metodologia, assim como exemplos de sua aplicação.

\section{Referências}

BROCKA, Bruce \& BROCKA, M. Suzanne. Gerenciamento da Qualidade. São Paulo: Akron Books, 1994.

CORREA, Carlos \& CORREA, Henrique L. Administração da Produção e Operações: Manufatura e Serviços, Uma Abordagem Estratégica. São Paulo: Atlas, 2008.

FARIAS FILHO J.R., SALLES M.T. Como agir estrategicamente para implementar o processo de gestão estratégica pela qualidade. ENEGEP, 1997.

GIL, Antonio Carlos. Como elaborar projetos de pesquisa. 4 ed. São Paulo: Atlas, 2009.

GONZALEZ, R. V. D. \& MARTINS, M. F. Melhoria contínua no ambiente ISO 9001:2000: estudo de caso em duas empresas do setor automobilístico. Revista Produção. Vol. 17, no. 3, p.592-603, 2007.

ISHIKAWA, Kaoru. Controle da Qualidade Total: À Maneira Japonesa. Rio de Janeiro: Campus, 1993.

JURAN, Joseph M. Controle da Qualidade: Handbook. São Paulo: Makron, 1991.

LAUGENI, Fernando P. \& MARTINS, Petronio G. Administração da Produção. 2 ed. São Paulo: Saraiva, 2005

OHNO, Taiichi. O Sistema Toyota de Produção: Além da Produção em Larga Escala. Porto Alegre: Bookman, 1997.

PALADINI, Edson P. Gestão Estratégica da Qualidade: Princípios, Métodos e Processos.2.ed. São Paulo: Atlas, 2009.

PARANHOS FILHO, Moacyr. Gestão da Produção Industrial. Curitiba: IBPEX, 2007.

SASHKIN, Kenneth J. \& KISE, Marshall. Gestão da qualidade total na prática. Rio de Janeiro: Campus, 1994.

SEBRAE. Manual de Ferramentas da Qualidade. Agosto, 2005.

SELEME, Robson \& STADLER, Humberto. Controle da Qualidade: as Ferramentas Essenciais. Curitiba: IBPEX, 2008 
SEVERINO, Antônio Joaquim. Metodologia do Trabalho Científico. 23 ed. São Paulo: Cortez Editora, 2007.

VERGUEIRO, Waldomiro. Qualidade em serviços de informação. São Paulo: Arte \& Ciência, 2002.

WERKEMA, Maria C. C. Ferramentas Estatísticas Básicas para o Gerenciamento de Processos. Belo Horizonte: Fundação Christiano Ottoni, 1995. 